\title{
In-Cylinder Heat Transfer in an Ericsson Engine Prototype
}

\author{
A. FULA ${ }^{1,2}$, P. STOUFFS ${ }^{1}$ and F.SIERRA ${ }^{2}$ \\ ${ }^{1}$ Laboratoire de Thermique, Energétique et Procédés \\ Université de Pau et des Pays de l’Adour 64000, Pau, France. \\ e-mail: pascal.stouffs@univ-pau.fr \\ ${ }^{2}$ Facultad de Ingenieria - Laboratorio Máquinas Térmicas y Energias Renovables \\ Universidad Nacional de Colombia - Carrera 30 No 45 a 03 Edificio 401, Bogotá, Colombia. \\ Phone 3165000 xt 11130, e-mail: mafula@unal.edu.co fesierrav@ unal.edu.co
}

\begin{abstract}
An Ericsson engine is an external heat supply engine working according to a Joule thermodynamic cycle. It is based on reciprocating piston-cylinder machines. Such engines are especially interesting for low power solar energy conversion and micro-CHP from conventional fossil fuels or from biomass. An Ericsson engine prototype has been designed and realized. Due to the geometrical configuration of the compression space of this prototype, in-cylinder fluid wall heat transfer can be important. The influence of this heat transfer on the engine performance is modelled and the main results are presented. The experimental setup designed to study the in-cylinder heat transfer is presented.
\end{abstract}

\section{Key words}

Solar energy conversion, biomass energy conversion, Ericsson engine, hot air engines, distributed generation, cylinder wall heat transfer.

\section{Introduction}

In 2005 in Colombia near one million of the 45 million Colombians people were living in areas not grid connected or suffering fuel poverty [1]. The issue of the Resolution "PROURE" $\mathrm{N}^{\circ} 180919$ of June 1, 2010 opens possibilities for alternative energies [2]. With the search for alternatives to fossil fuels, very old historical heat engines reappears [3] in order to allow the conversion of renewable energy as solar, biomass or biogas, but also the use of fossil fuels like coal, gas or oil. The so-called "hot air engines" have excellent energetic versatility so that they are readily adapted for this kind of use. Those are defined as external heat supply engines, with separate compression and expansion cylinders, with or without regenerator or recuperator, and with a single phase gaseous working fluid [4]. The family of hot air engines is divided in two subgroups: Stirling engines, invented in 1816, have no valves (Figure 1) whereas Ericsson engines, invented in 1833 (Figure 2) have valves in order to isolate the cylinders.

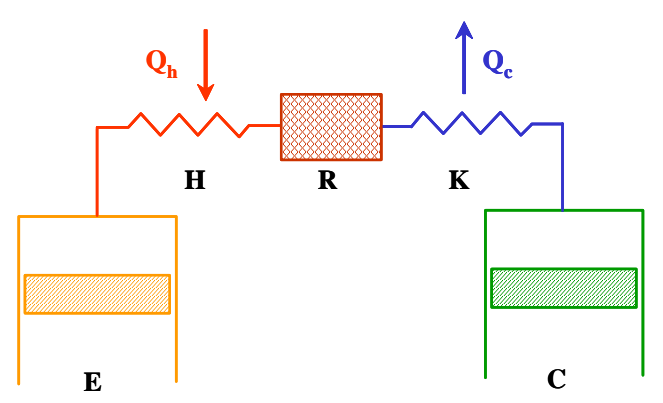

Fig. 1. Principle of the Stirling engine.

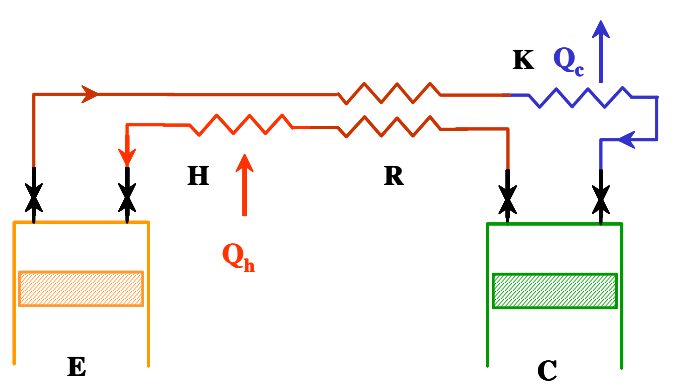

Fig. 2. Principle of the Ericsson engine.

The Stirling engine has benefited from many research and development efforts in the second half of the $\mathrm{XX}^{\text {th }}$ century. But his "cousin" the Ericsson engine has not enjoyed the same interest [5] despite having significant advantages over the Stirling. Amongst them, it is worth to note that the Ericsson engine heat exchangers are not dead volumes, whereas the Stirling engine heat exchangers designer has to face a difficult compromise between as large heat transfer areas as possible, but as small heat exchanger volumes as possible.

Besides, Ericsson engines can operate with air in open cycle and low pressure ratio. This allows to design Ericsson engines that can be built or adapted in countries with little technological development for rural energy applications or distributed generation. 
The theoretical Ericsson cycle is made up of two isothermal processes and two isobaric processes. Unfortunately it is not suitable to describe an ideal Ericsson engine. Indeed due to the lack of heat exchange surface in the cylinder, the heat transfers between the working fluid and the hot and cold sources take place in external heat exchangers adjacent to the cylinders instead of through the cylinders wall. So, the cycle made up of two isentropic and two isobaric processes, usually called the Brayton or Joule cycle, seems more suitable to describe the Ericsson engine. This theoretical cycle is often used to describe the gas turbine engine. Actually, the Ericsson engine is a special gas turbine engine where the turbomachines are replaced by reciprocating systems. The engine designed by Joule was a simplified version of the engine built by Ericsson twenty years earlier, as the Joule engine had no recuperator.

As for Stirling engines, Ericsson engines are specially interesting for thermodynamic solar energy conversion and for micro-cogeneration. However, in both fields, Ericsson engines can have some specific advantages on Stirling engines.

In the field of solar energy conversion, most current existing systems for low power thermodynamic solar energy conversion are based on the 'Dish/Stirling' technology $[6,7]$, which relies on high temperature Stirling engines and requires a high solar energy concentration ratio (Figure 3).

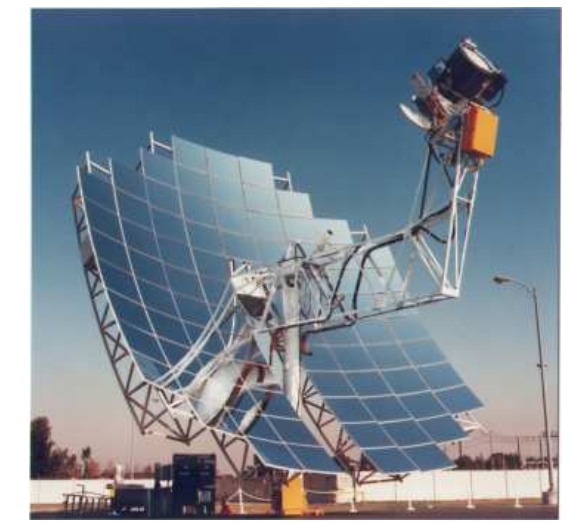

Fig. 3. SES solar Dish/Stirling system (Source: www.stirlingenergy.com).

However it is clear that these systems are quite heavy, leading to high costs. Especially the parabolic 'dish' concentrator, the sun tracking system and the engine fixation at the concentrator focus are quite expensive. Also the high pressure high temperature engine requires an expensive technology.

Due to the need to minimize the heater volume, solar energy conversion by means of a Stirling engine implies to focus solar beams on a point, that means to use an expensive parabolic dish. Using an Ericsson engine allows large heater thus linear solar concentrator such as parabolic trough. Modelling results have shown that the coupling of a parabolic trough with an open cycle Ericsson engine (Figure 4) could lead to a yearly global efficiency higher than $10 \%$ while using a low tech and cheap system $[8,9]$.
Unlike internal combustion engines, hot air engines generate low noise and do not need frequent maintenance. Therefore they are particularly suited for low-power combined heat and power (CHP), for residential applications for instance. Up to now, several Stirling engines have been designed for microcogeneration $[10,11]$. However it has been shown that a natural gas CHP system based on an open cycle Ericsson engine could be interesting and profitable [12].

Furthermore there is a great interest for microcogeneration systems based on wood energy. The only system up to now is based on a Stirling engine fuelled by wood pellets. It has been developed by Sunmachine. Unfortunately it is not yet commercially available. Other tests have been carried out by coupling a Stirling engine in a conventional wood boiler. One of the main problems consists in the fouling of the Stirling heater and the difficulty to clean its surface due to its compactness [13, 14]. For this application the Ericsson engine is also interesting since the heater does not need to be compact and may be designed according to heat transfer and fouling consideration only.

\section{The prototype}

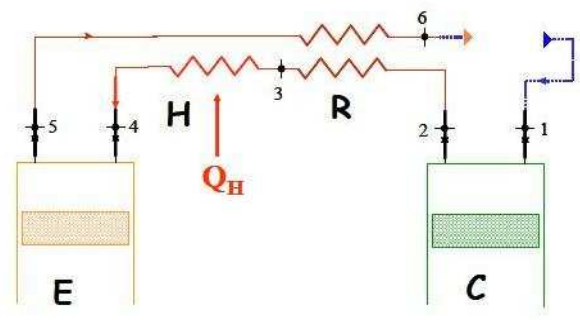

Fig. 4. Basic scheme of the Ericsson engine with heat recovery for Joule-Brayton cycle.

According to the modelling results [8], the prototype is designed to work with air in open cycle as the working fluid. Figure 4 shows the configuration of the system. Figure 5 is a picture of the prototype in our laboratory.

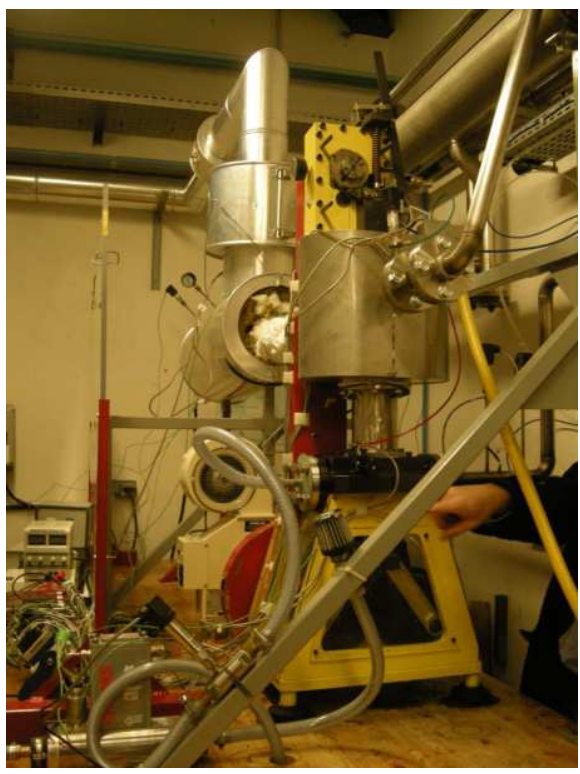

Fig. 5. The Ericsson engine prototype. 
The nominal pressure ratio is 3 and the maximum operating temperature is $650{ }^{\circ} \mathrm{C}$. The prototype expansion cylinder capacity is $0.65 \mathrm{dm}^{3}$. The expansion cylinder bore is $80 \mathrm{~mm}$, the piston stroke is $129 \mathrm{~mm}$ and the maximum rotation speed is $950 \mathrm{rpm}$.

This prototype has been originally designed to convert small scale concentrated solar energy into electricity. The collaboration with the Renewable Energy Laboratory from the Universidad Nacional in Colombia seeks to hybridize the prototype in order to be able to operate also with biogas.

While designing the prototype, it has been chosen to have a single cylinder with a double acting piston. Figure 6 presents a sketch of the configuration chosen. The upper face of the piston closes the expansion space E, while the lower face of the piston delimits the compression space C. This configuration maximizes the mechanical efficiency since the mechanical power given to the crankshaft is the net mechanical power, that is the power produced by the expansion cylinder reduced by the power consumed by the compression cylinder.

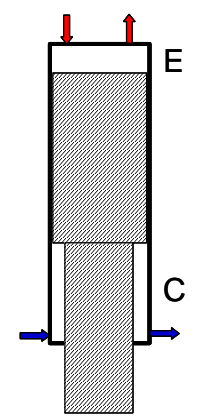

Fig. 6. Configuration of the double acting piston, with the expansion space $\mathrm{E}$, and the compression space $\mathrm{C}$.

\section{Heat transfer in the cylinder}

Due to the fact that the compression cylinder capacity has to be smaller than the expansion cylinder capacity, the double-acting configuration implies to have a large diameter piston rod in the compression space (Figure 6). Moreover the stroke for this first prototype has been chosen to be $122 \mathrm{~mm}$, much larger than the cylinder bore of $80 \mathrm{~mm}$. Due to piston rings consideration, the lower part of the cylinder wall, the piston rod and the lower side of the piston are water cooled. The compression space has thus a high ratio surface/volume with low temperature wall surface.

Presumably that effective cooling of the compression chamber will reduce the compression energy required, will increase the heat recovery in the recuperator heat exchanger, but will require increased thermal power to be supplied by the heat source $(\mathrm{H})$. In addition, it is also known [15] that in reciprocating positive displacement machines, alternate fluid - cylinder wall heat transfer can be a loss of energy. Indeed, during its expansion, the mass of fluid trapped in the death volume of the cylinder does not give back the energy accumulated during its compression. Under these conditions, it is possible that the heat exchange between the working fluid and the cylinder walls can have a significant influence on the engine performance.

In order to evaluate this influence, a model of the Ericsson engine has been developed [16]. In this model, three different correlations have been used to calculate the in-cylinder fluid to wall heat transfer, the Eichelberg correlation [17], the Woschni correlation [18] and the Hohenberg correlation [19].

The modelling assumptions and the numerical resolution procedure are described in [16]. For the simulation results presented hereafter, the atmospheric air temperature at the inlet of the compression space $\mathrm{C}$ is set to $300 \mathrm{~K}$, identical to the compression space wall temperature. In theses simulations an efficient water cooling of the compression cylinder wall is thus assumed. The temperature of the compressed air at the inlet of the expansion space $\mathrm{E}$ is assumed to be $923 \mathrm{~K}$, and the expansion space wall temperature is set to $850 \mathrm{~K}$.

Figures 7 and 8 present the indicated diagrams of the compression and the expansion spaces obtained in the adiabatic case, that is without fluid-wall heat transfer in the cylinder. The times of inlet valve opening (IVO), inlet valve closure (IVC), exhaust valve opening (EVO) and exhaust valve closure (EVC) are marked in these figures. The compression space diagram (fig. 7) is anticlockwise (mechanical work consumption) while the expansion space diagram (fig. 8) is clockwise (mechanical work production).

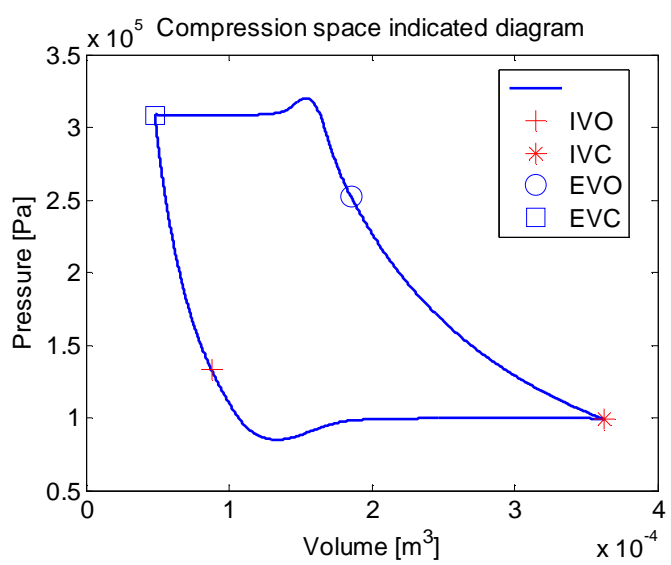

Fig. 7. Compression space indicated diagram (adiabatic case).

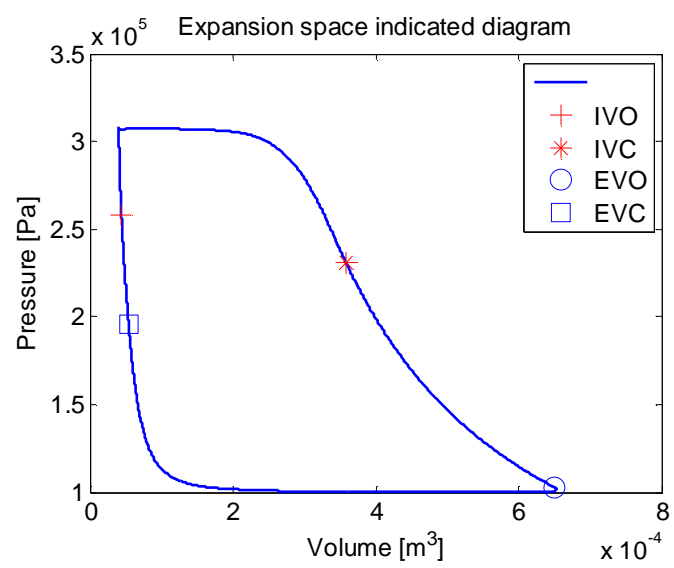

Fig. 8. Expansion space indicated diagram (adiabatic case). 
Figures 9 and 10 show the evolution of the instantaneous transfer coefficients in the compression and expansion cylinders for the 4 cases considered: adiabatic (solid line), heat transfer modelled by the correlation of Hohenberg (dotted line), Eichelberg (dashed) or Woschni (dashed dotted). The three correlations give similar evolutions, but with vertical shift. For the compression cylinder, the correlation of Hohenberg gives the greatest transfer coefficient, while the correlation of Eichelberg gives the greatest transfer coefficient for the expansion cylinder, wherein the differences between the results obtained by the correlations are greater.

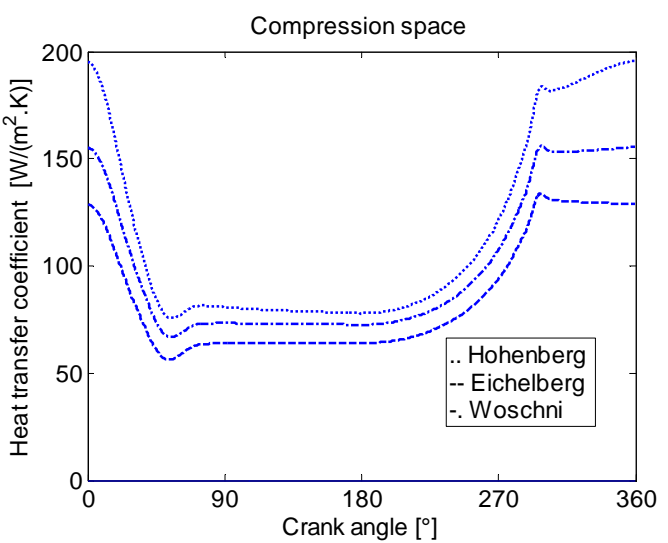

Fig. 9. Compression space heat transfer coefficient.

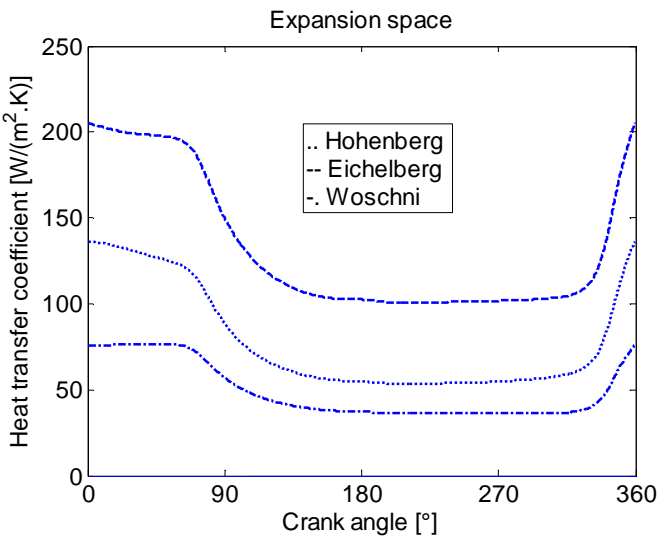

Fig. 10. Expansion space heat transfer coefficient.

Figures 11 and 12 show the evolution of the instantaneous fluid temperature in the compression and expansion spaces. For the compression cylinder, the 3 correlations give quite similar temperature evolutions, but quite different from the adiabatic case. For the expansion cylinder, the temperature evolutions are quite different during the exhaust phase according to the correlation considered. Figures 13 and 14 show the entropy diagram of the fluid state in the compression and expansion cylinders for each of the four cases considered. This diagram is reduced to a vertical line in the adiabatic case, except for a small loop due to the mixing during the inlet phase (at low temperature for the compression cylinder, fig. 13, and high temperature for the expansion cylinder, fig. 14). It is also observed that the cooling of the cylinder walls leads to an energy consuming cycle in the compression cylinder: the mechanical work produced by the expansion of the fluid trapped in the dead volume is lower than the work consumed during compression because of the fluid cooling. This negative effect of the dead volume is greater when taking the Hohenberg correlation into account. This applies to the expansion cylinder where the alternate heat transfer also creates a 'negative loop' in the entropy diagram. This time the Eichelberg correlation leads to the greatest loss of mechanical energy.

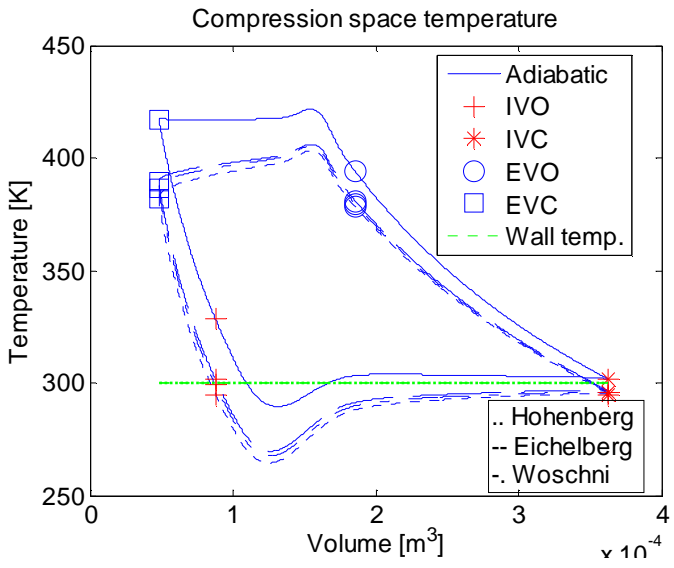

Fig. 11. Compression space temperature.

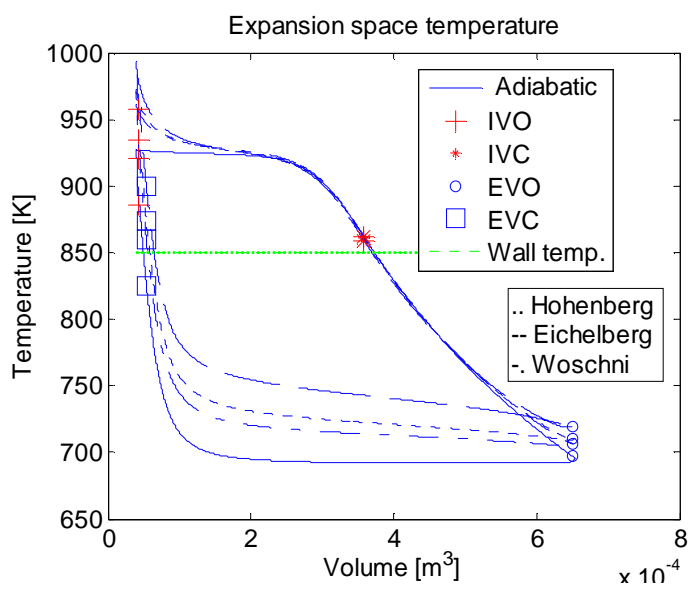

Fig. 12. Expansion space temperature.

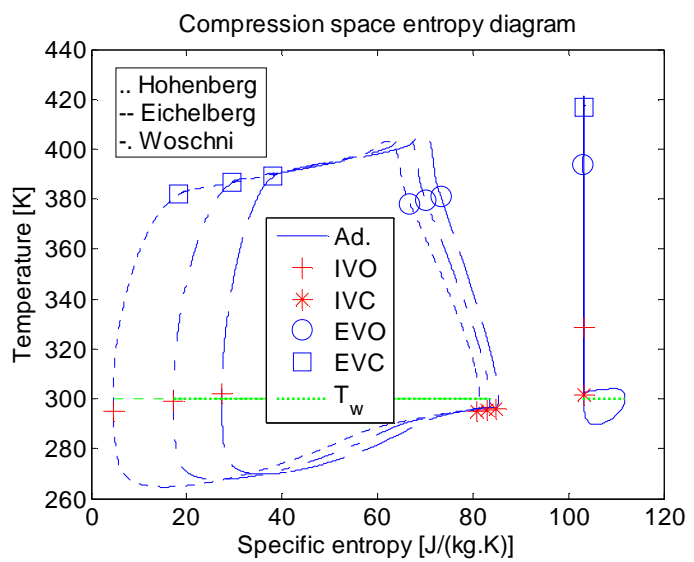

Fig. 13. Compression space temperature-entropy diagram.

Finally, figure 15 shows the overall entropy diagram of the cycle in the four cases considered. The heat transfer does not affect very much the global cycle evolution. In particular the heater pressure is hardly modified by heat transfer. On the other hand, temperatures $\mathrm{T}_{2}, \mathrm{~T}_{3}, \mathrm{~T}_{5}$ and $\mathrm{T}_{6}$ at the inlets and outlets of the recuperator heat exchanger are quite modified by in-cylinder heat transfer. 


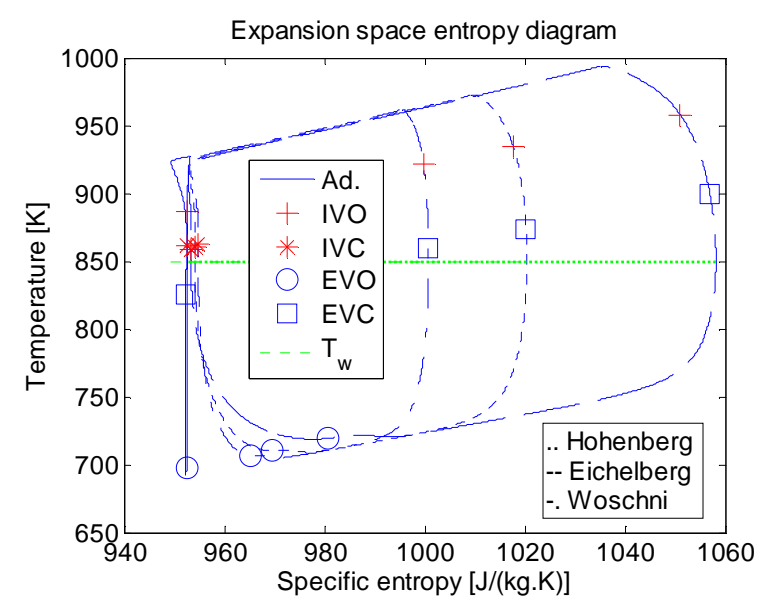

Fig. 14. Expansion space temperature-entropy diagram.

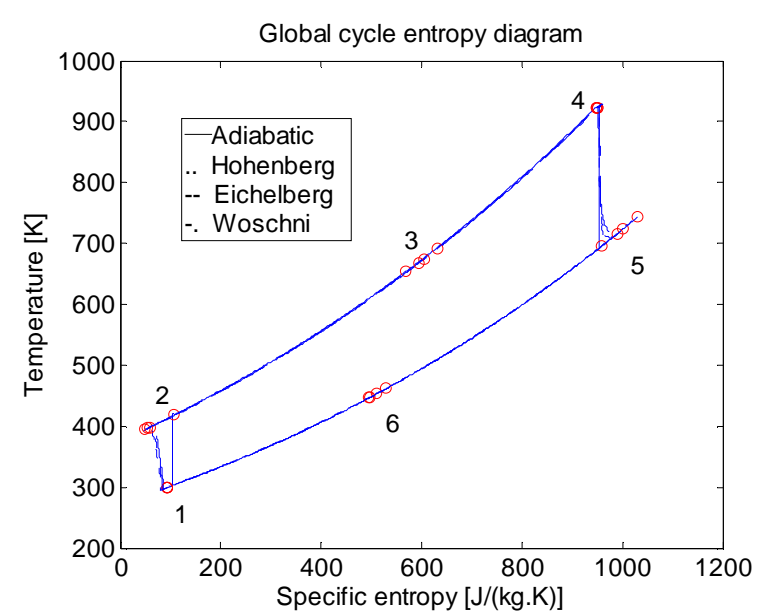

Fig. 14. Global cycle temperature-entropy diagram.

This theoretical study [16] shows that heat transfer to the walls can significantly modify the temperature at the inlets and outlets of the recuperator heat exchanger, but that it does not affect very much the fluid mass flowrate, the pressure at the inlet of the expansion cylinder, the net power and the efficiency of the whole Ericsson engine.

\section{Experimental setup}

It has thus been decided to carry out an experimental investigation on in-cylinder heat transfer. This study is now in progress, so that only the experimental setup can be presented.

Figure 15 presents a sketch of the Ericsson engine. In normal engine operation, the air which acts as the working fluid of the engine is taken from the environment through the filter F. It passes through the flowmeter DEB then enters the compression space (in cyan). After compression, the air receives heat from the heat recovery "recuperator" exchanger RST1 and from the electrical heater REH. A buffer tank RST2 is inserted in the circuit before the expansion space. Afterwards the expanded air gives heat to the compressed air in the recuperator HS before being discharged to the atmosphere.

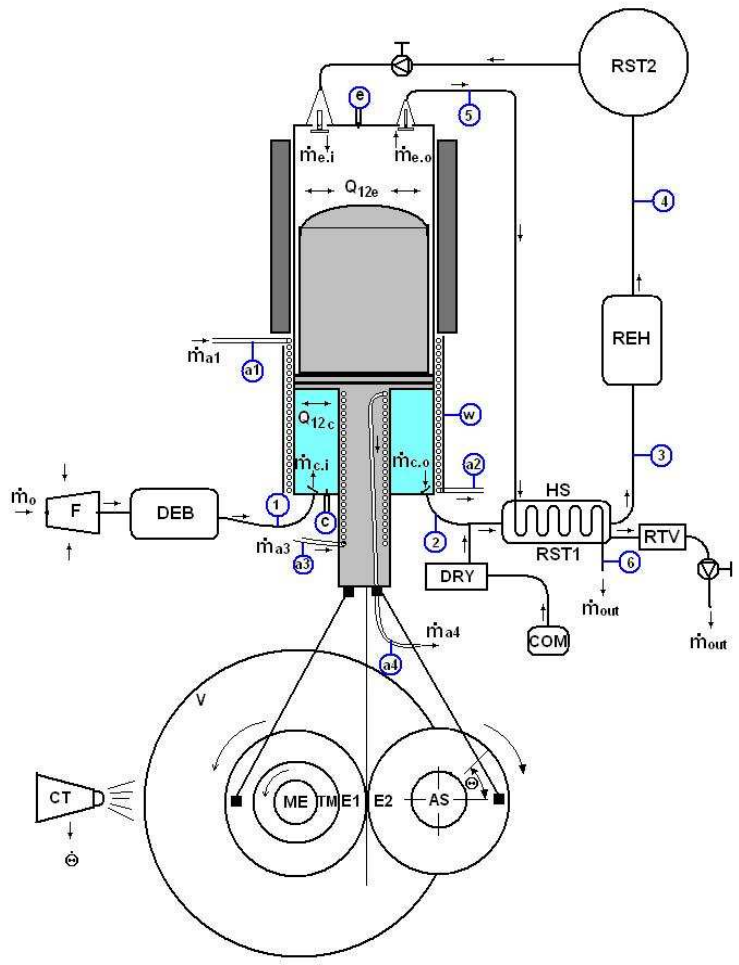

Fig. 15. The experimental setup

If only the expansion cylinder is to being tested, the valves of the compression space are maintained in open position and compressed air is delivered from the external compressor COM. It flows first through a dryer DRY (because the flowmeter DEB which can be inserted in this part of the circuit does not withstand humid air) and enters then the normal compressed air circuit.

For the present study of heat transfer in the compression cylinder, the valves of the expansion cylinder are maintained in open position. The engine is driven by the electrical motor ME. Atmospheric air is taken from the environment through the filter $\mathrm{F}$ and the flowmeter DEB. It flows through the compression space and the recuperator RST1 before being discharged to the atmosphere through the control valve RTV. This valve allows the compression space back pressure to be controlled. Water which temperature can be controlled in the range between $5{ }^{\circ} \mathrm{C}$ and $95{ }^{\circ} \mathrm{C}$ cools or heats the cylinder jacket (with the mass flowrate $\dot{m}_{a 1}$ ), the piston rod (with the mass flowrate $\dot{m}_{a 3}$ ) and the lower side of the piston (with the mass flowrate $\dot{m}_{a 4}$ ).

An incremental angular coder AS allows to calculate the instantaneous compression space volume. An optical tachymeter CT is also used to monitor the rotational speed. Three Keller-Druck pressure transducers (ref PR23S) are installed at the inlet duct (1), at the outlet duct (2) and also in the cylinder head (c). Together with the angular coder the latter allows to plot the $(\mathrm{p}, \mathrm{V})$ indicated diagram of the expansion space. Different 0.1 $\mathrm{mm} \mathrm{K}$ type thermocouples are also implemented in several locations of the air or water circuit. 
Besides this usual instrumentation, a $0.025 \mathrm{~mm}$ diameter $\mathrm{K}$ type micro-thermocouple is installed in the compressor cylinder head (c). This was specially built by Professor F. Lanzetta from the FEMTO Laboratory of the FrancheComte University (Belfort, France). Figure 16 shows the picture of the manufacturing process of the thermocouple just after being welded. Figure 17 presents the thermocouple mounted on the M10 fine threaded device ready to install. The response time of the thermocouple is estimated at $34 \mathrm{~ms}$ [20]. Unfortunately this device is very fragile.

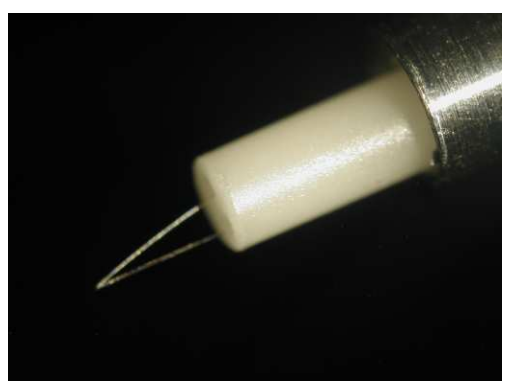

Fig. 16. $0.025 \mathrm{~mm}$ thermocouple wires welded.

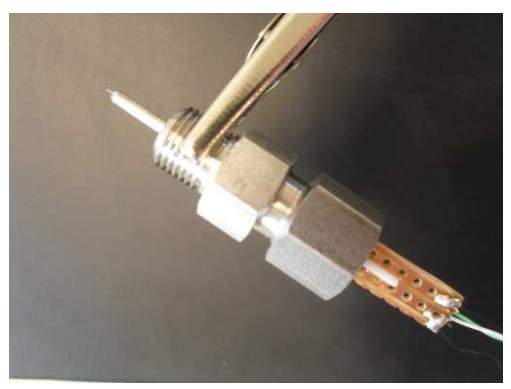

Fig. 17. The micro-thermocouple ready to use.

The measurement procedure is started only when the system attains a (periodical) stationary state. It is considered that the compressor, driven by the electric motor (ME), arrives to steady state once the cylinder wall temperature varies less than $0.1{ }^{\circ} \mathrm{C}$ during $60 \mathrm{~s}$. This could take between 20 and $28 \mathrm{~min}$.

\section{Conclusion}

Ericsson engines are appropriate for low power solar energy and biomass energy conversion. An Ericsson engine prototype has been designed and built. Due to the geometrical design of its compression space, the influence of in-cylinder fluid wall heat transfer is studied. The modelling results show that heat transfer to the walls can significantly modify the temperature at the inlets and outlets of the recuperator heat exchanger, but that it does not affect very much the fluid mass flowrate, the pressure at the inlet of the expansion cylinder, the net power and the efficiency of the whole Ericsson engine. The experimental setup designed to study the in-cylinder heat transfer is presented.

\section{References}

[1] UPME, Índices de Cobertura de Energía Eléctrica y Gas Natural, Ministerio de Minas y Energía, República De Colombia, 2005.
[2] Resolucion Proure, $\mathrm{N}^{\circ} 180919$, Ministerio de Minas y Energía, República De Colombia, June 1, 2010.

[3] Kolin I, Stirling Motor, Zagreb Univ. Publications Ltd, Zagreb, 1991.

[4] Stouffs P., «Does the Ericsson engine deserve more consideration than the Stirling engine? », Proc. European Stirling Forum ECOS, 2002.

[5] Touré A., Étude théorique et expérimentale d'un moteur Ericsson à cycle de Joule pour conversion thermodynamique de l'énergie solaire ou pour microcogénération, PhD Thesis, Université de Pau et des Pays de l'Adour, France, 2010.

[6] Stine W.B., Diver R.B., A Compendium of Solar Dish/Stirling Technology, Rapport SAND93-7026 UC-236, Sandia National Laboratories, Albuquerque 1994; updated versions available at www.grc.nasa.gov, 2004.

[7] Bancha Kongtragool, Somchai Wongwises, A review of solar-powered Stirling engines and low temperature differential Stirling engines, Renewable and sustainable Energy Reviews, 7, pp.131-134, 2003.

[8] Alaphilippe, M., Recherche d'un nouveau procédé de conversion thermodynamique de l'énergie solaire, en vue de son application à la cogénération de petite puissance, $\mathrm{PhD}$ thesis, Université de Pau et des Pays de l'Adour, Pau, 2007.

[9] Alaphilippe, M., Stouffs, P., Instantaneous and yearly electric production of a low power thermodynamic solar energy conversion system: modeling results, Proceedings of ECOS 2008, Krakow, June 24-27, 2008.

[10] Pehnt, M., Cames, M., Fischer, C., Praetorius, B., Schneider, L., Schumacher, K., Vo $\beta$, J.P., Micro Cogeneration: Towards Decentralized Energy Systems, Springer-Verlag Berlin Heidelberg, 2006.

[11] Onovwiona, H.I., Ugursal, V.I., Residential cogeneration systems: review of the current technology, Renewable and Sustainable Energy Reviews, Vol. 10, pp 389-431, 2006.

[12] Bonnet, S., Alaphilippe, M., Stouffs, P., Energy, exergy and cost analysis of a micro-cogeneration system based on an Ericsson engine, Int. J. Therm. Sci., Vol. 44, $\mathrm{N}^{\circ} 12$, p. 1161-1168, Elsevier ${ }^{\text {Science }}$, Oxford, 2005.

[13] Kammerich, B., Heat and Electricity based on Wood: Short report of a field test with a micro-Stirling engine and a log boiler, International Stirling Forum, ISF 2008, Osnabrück, September 23-24, 2008.

[14] Sicre B., Schüle K., Wapler J., Maurath T., Development of a wood-fired micro-CHP-system with Stirling engine for residential applications, International Stirling Forum, ISF 2008, Osnabrück, September 23-24, 2008.

[15] Stouffs P., Tazerout M., Wauters P., Thermodynamic analysis of reciprocating compressors, Int. J. Therm. Sci., 40-1 (2001), 52-66.

[16] Fula Rojas M.A., Sierra Vargas F.E., Stouffs P., Etude théorique de l'influence des transferts thermiques au travers des parois des cylindres d'un moteur ERICSSON, Actes du Colloque de la Société Française de Thermique SFT 2012. Elsevier.

[17] Eichelberg G, Some new investigations on old combustion engine problems, Engineering, vol. 148, 1939, p. 463 - 446 et $547-560$.

[18] Woschni G, A universally applicable equation for the instantaneous heat transfer coefficient in the internal combustion engine, SAE Paper no. 670931; 1967.

[19] Hohenberg GF, Advanced Approaches for Heat Transfer Calculations, Warrendale, PA: SAE International, 1979.

[20] Lanzetta F., Mesure de température à l'aide de microthermocouples : principe, choix technologiques et modes d'implantations, Journées "Mesure de Température", Salon Mesurexpo, Société Française de Physique et Société Française de Thermique, Paris, oct. 2006. 